\title{
West Nile virus in humans, Greece, 2018: the largest seasonal number of cases, 9 years after its emergence in the country
}

Danai Pervanidou ${ }^{1}$, Annita Vakali ${ }^{1}$, Theano Georgakopoulou ${ }^{1}$, Takis Panagiotopoulos ${ }^{2}$, Eleni Patsoula ${ }^{2}$, George Koliopoulos ${ }^{3}$ , Constantina Politis ${ }^{1}$, Kostas Stamoulis 4 , Elpida Gavana ${ }^{5}$, Styliani Pappa ${ }^{5}$, Maria Mavrouli6, Maria Emmanouil ${ }^{7}$, George Sourvinos $^{8}$, Andreas Mentis ${ }^{7}$, Athanassios Tsakris ${ }^{6}$, Christos Hadjichristodoulou ${ }^{9}$, Sotirios Tsiodras ${ }^{1,10}$, Anna Papa ${ }^{5}$

1. Hellenic National Public Health Organization/former Hellenic Center for Disease Control \& Prevention, Athens, Greece

2. School of Public Health, Faculty of Public Health Policy, University of West Attica, Athens, Greece

3. Benaki Phytopathological Institute, Athens, Greece

4. Hellenic National Blood Transfusion Center, Athens, Greece

5. National Reference Center for Arboviruses and Haemorrhagic Fever Viruses, Department of Microbiology, Medical School, Aristotle University of Thessaloniki, Thessaloniki, Greece

6. Department of Microbiology, Medical School, National and Kapodistrian University of Athens, Athens, Greece

7. Diagnostic Services Laboratory, Public Health Laboratories, Hellenic Pasteur Institute, Athens, Greece

8. Laboratory of Clinical Virology, Medical School, University of Crete, Heraklion, Crete, Greece

9. Laboratory of Hygiene and Epidemiology, Medical School, University of Thessaly, Larisa, Greece

10. National and Kapodistrian University of Athens, Athens, Greece

Correspondence: Danai Pervanidou (d.pervanidou@eody.gov.gr)

Citation style for this article:

Pervanidou Danai, Vakali Annita, Georgakopoulou Theano, Panagiotopoulos Takis, Patsoula Eleni, Koliopoulos George, Politis Constantina, Stamoulis Kostas , Gavana Elpida, Pappa Styliani, Mavrouli Maria, Emmanouil Maria, Sourvinos George, Mentis Andreas, Tsakris Athanassios, Hadjichristodoulou Christos, , Gavana Elpida, Pappa Styliani, Mavrouli Maria, Emmanouil Maria, Sourvinos George, Mentis Andreas, Tsakris Athanassios, Hadjichristodoulou Christos, Surveill. 2020;25(32):pii=1900543. https://doi.org/10.2807/1560-7917.ES.2020.25.32.1900543

Background: Human cases of West Nile virus (WNV) infection are recorded since 2010 in Greece, with seasonal outbreaks occurring almost annually. Enhanced surveillance has been implemented since 2010 , to promptly characterise cases' temporal and geographical distribution and inform authorities for implementation of appropriate measures (mosquito control, health education, blood safety). Aim: We describe the epidemiology of WNV human infections in Greece focusing on the 2018 season. Methods: The National Public Health Organization advised physicians to test all suspect WNV infection cases and refer samples to reference laboratories. Laboratories notified diagnosed cases on a daily basis. Treating physicians, patients, and infected blood donors were interviewed within 48 hours after diagnosis and the probable infection location was identified. Hospitalised cases were followed up until discharge. Results: A total of 317 autochthonous WNV infection cases were diagnosed in 2018. Among them, 243 cases had neuroinvasive disease (WNND), representing a $23 \%$ increase of WNND cases compared with 2010, the previous most intense season. There were 51 deaths. Cases started occurring from week 22, earlier than usual. Both rural and urban areas were affected, with $86(26 \%$ of the total) municipalities belonging to seven ( $54 \%$ of the total) regions recording cases. Two major epicentres were identified in Attica and Central Macedonia regions. Conclusions: The largest number of human cases of WNV infection ever recorded in Greece occurred in 2018, with a wide geographical distribution, suggesting intense virus circulation. Enhanced surveillance is vital for the early detection of human cases and the prompt implementation of response measures.

\section{Introduction}

West Nile virus (WNV) is a flavivirus primarily transmitted to humans, equids and other mammals through the bites of infected mosquitoes, mainly of the Culex genus [1]. WNV lineages 1 and 2 have been associated with significant outbreaks in humans [1]. Birds serve as reservoir hosts [1], whereas humans and equids are considered dead-end hosts [2-4]. Transmission through blood transfusion and organ transplantation can occasionally occur, and other rare modes of transmission have been also recorded, such as transmission from mother to child during pregnancy, delivery, or breastfeeding, and in laboratory settings $[1,3]$.

Most humans infected with WNV remain asymptomatic; ca $20 \%$ develop a disease with fever and/or other influenza-like symptoms known as West Nile fever (WNF), and less than $1 \%$ develop neuroinvasive disease (WNND), such as encephalitis, meningitis or more rarely - acute flaccid paralysis (AFP) $[5,6]$. Elderly and immunocompromised persons are at higher risk of developing severe disease and having a fatal outcome [7]. No specific treatment or vaccine exists to cure or prevent the disease in humans. 
WNV infection is considered endemo-epidemic in parts of Europe, affecting countries in southern, eastern and western Europe $[8,9]$ and is considered a re-emerging public health challenge in the European Union (EU), with annual seasonal outbreaks during the summer months and early autumn.

Migratory birds are thought to be the source of introductions of new virus strains into previously unaffected areas [4,10-15]. In Europe the virus has been introduced through migratory birds from Africa $[16,17]$ and its circulation is probably greatly influenced by the flying routes of migratory bird species [18]. WNV overwinters in mosquitoes [19], and overwintering in local bird species in Europe cannot be excluded [8,17]. WNV lineage 1 was the main lineage circulating in Europe $[10,20]$ from the 1960 s, whereas lineage 2 spread over central and southern eastern Europe [21,22] since 2004 causing major outbreaks [23-27]. In 2018, the largest number of cases of WNV infection was recorded in Europe, with their total number exceeding the cumulative number of all cases recorded in the previous 7 years, between 2010 and 2017 [28].

In Greece, human cases of WNV infections have been recorded since 2010 [29,30], with seasonal outbreaks (from end June to early October) on an almost annual basis [31-35]. The causative WNV strain (Nea Santa-Greece-2010) belongs to the Central European/ Hungarian subclade of WNV lineage $2[25,36,37]$. This strain was detected in patients, blood donors, mosquitoes, horses and birds in many seasons from 2010 to 2017 [25,35,38-47].

Enhanced surveillance of human WNV infection is annually implemented since 2010, from May to November, by the Hellenic National Public Health Organization (NPHO)/former Hellenic Center for Disease Control \& Prevention (HCDCP). The surveillance is undertaken to promptly identify human cases of WNV infection and monitor their temporal and geographical distribution. It also has the objective to detect cases and WNVaffected areas, in a timely fashion, to inform national and local authorities for the implementation of appropriate response measures, including blood safety measures, intensified vector control and communication campaigns. In the long term, surveillance aims to quantify the disease burden, and identify seasonal, geographical and demographic patterns, and populations at risk [31]. Herein, we describe the clinical characteristics and laboratory findings of human cases as well as their distribution in time and place during 2018 in Greece.

\section{Methods}

\section{Surveillance}

As part of routine procedures implemented over the last years before the beginning of each WNV season, informative material was sent by the $\mathrm{NPHO} /$ former HCDCP to all healthcare facilities and medical associations around the country in May 2018, to raise awareness of physicians concerning the diagnosis of WNV infection. The NPHO/former HCDCP prompted physicians to further conduct laboratory testing of all WNV infection suspected cases, who were defined as any person with acute onset of neurological syndromes (encephalitis, meningitis or myelitis), as well as any person with non-neurological illness but unexplained fever. NPHO/former HCDCP recommended referral of samples to specific specialised laboratories for testing.

The Vector-borne Diseases (VBD) Office of the NPHO/ former HCDCP implemented active laboratory-based surveillance, throughout the transmission season, with daily communication with three reference/specialised laboratories (further described in the "laboratory methods' section) and daily reporting of diagnosed cases to NPHO/former HCDCP. Laboratory diagnosis was freeof-charge for patients in the reference/specialised laboratories, reimbursed by NPHO/former HCDCP.

Blood safety authorities informed NPHO/former HCDCP about any infections diagnosed among blood donors tested in affected areas.

The EU case definition of WNV infection [48] was used with slight modifications, in that only laboratory - and not epidemiological - criteria were used to define probable cases; a confirmed case was defined as a person with either PCR detection of WNV nucleic acid in any biological specimen, such as blood, cerebrospinal fluid (CSF) or urine, or detection of a WNV specific IgM antibody response in CSF, or WNV IgM and IgG antibody response and confirmation by neutralisation tests. $\mathrm{A}$ probable case was defined as a person with positive IgM antibody response only in serum. Asymptomatic infections detected during blood screening in affected areas were also included - for the first time in 2018 in the case definition.

Municipalities (the lowest administrative unit) where at least one human laboratory-diagnosed case of WNV infection was exposed during the 2018 period were defined as affected areas.

\section{Data collection}

The VBD Office of the NPHO/former HCDCP investigated and recorded all cases with laboratory-diagnosed WNV infection, symptomatic or not, with or without neuroinvasive disease. The disease was classified as WNND (encephalitis, meningitis, meningo-encephalitis or myelitis/AFP) based on the treating physicians' clinical assessment and/or additional laboratory and/or imaging findings, when available.

Cases were investigated by the VBD Office with indepth telephone interviews with the patients, or if this was not possible, with their close relatives, ideally within 24-48 hours after diagnosis, using a standardised investigation form, to obtain detailed travel history during incubation period (2-14 days before symptom 
TABLE 1

Numbers of total WNV affected areas a infection cases, WNND cases and related deaths and case fatality per year, as well as annual incidence of total WNND cases, Greece, 2010-2018 $(\mathrm{n}=989$ WNV infection cases)

\begin{tabular}{|c|c|c|c|c|c|c|c|c|c|}
\hline Criteria & 2010 & 2011 & 2012 & 2013 & 2014 & 2015 & 2016 & 2017 & $2018^{b}$ \\
\hline Number of affected municipalities & 38 & 46 & 42 & 35 & 7 & 0 & 0 & 10 & 86 \\
\hline Number of affected regional units ${ }^{c}$ & 11 & 21 & 19 & 12 & 4 & 0 & 0 & 6 & 24 \\
\hline Number of affected regions & 5 & 7 & 8 & 5 & 3 & 0 & 0 & 3 & 7 \\
\hline Number of WNV infection cases & 262 & 100 & 161 & 86 & 15 & 0 & 0 & 48 & 317 \\
\hline Number of WNND cases & 197 & 75 & 109 & 51 & 14 & 0 & 0 & 28 & 243 \\
\hline Percentage of WNND cases & $75 \%$ & $75 \%$ & $68 \%$ & $59 \%$ & $93 \%$ & NA & NA & $58 \%$ & $77 \%$ \\
\hline Incidence of WNND cases (per 100,000 population) & 1.8 & 0.7 & 1.0 & 0.5 & 0.1 & 0 & 0 & 0.3 & 2.2 \\
\hline Number of fatal cases with WNV infection & 35 & 9 & 18 & 11 & 6 & 0 & 0 & 5 & 51 \\
\hline Case fatality among cases with WNV infection & $13 \%$ & $9 \%$ & $11 \%$ & $13 \%$ & $40 \%$ & NA & NA & $10 \%$ & $16 \%$ \\
\hline Number of fatal cases with WNND & 33 & 9 & 18 & 10 & 6 & 0 & 0 & 5 & 48 \\
\hline Case fatality of cases with WNND & $17 \%$ & $12 \%$ & $17 \%$ & $20 \%$ & $43 \%$ & NA & NA & $18 \%$ & $20 \%$ \\
\hline
\end{tabular}

NA: not applicable; NUTS: nomenclature of territorial units for statistics; WNND: West Nile virus neuroinvasive disease; WNV: West Nile virus.

a Number of affected municipalities, regional unitsb, and regions with $\geq 1$ case of WNV infection.

${ }^{b}$ To put the 2018 data in a further more recent perspective, the numbers for 2019 were: 56 affected municipalities, 19 affected regional units, five affected regions, 227 WNV infection cases, 140 WNND cases (corresponding to $62 \%$ of WNV infection cases), 1.3 WNND cases per 100,000 population, 35 fatal cases with WNV infection (corresponding to a case fatality of $15 \%$ among cases with WNV infection) and 33 fatal cases with WNND (representing a case fatality of $24 \%$ in cases with WNND).

'Regional units: NUTS3.

onset) and identify the probable place of exposure. In case of complex travel history, the most probable place of infection was defined - after risk assessment - by a multi-sectoral working group of the Ministry of Health dedicated to designate the areas affected by VBD.

The treating physician was interviewed to record the clinical manifestations and underlying diseases of each patient.

The data collected included: demographic characteristics, clinical manifestations, underlying chronic diseases, dates of onset of symptoms, hospitalisation, diagnosis, discharge, admission and discharge from intensive care unit (ICU), potential risk factors, laboratory results, detailed travel history during the maximum incubation period. Hospitalised patients were actively followed up on a daily basis, by telephone, and their outcome at the end of hospitalisation was recorded.

The NPHO/former HCDCP informed on a daily basis, by e-mails, national, regional and local public health authorities about the cases and their probable place of exposure, in order to implement responsive preventive measures (vector control, communication activities, blood safety).

Weekly surveillance reports were published on the $\mathrm{NPHO} /$ former HCDCP website.

\section{Laboratory methods}

On a daily basis, the VBD Office of the NPHO/former HCDCP received laboratory data of the diagnosed cases mainly from three laboratories (including the National Reference Center for Arboviruses and Haemorrhagic Fever Viruses, Department of Microbiology, Medical School, Aristotle University of
Thessaloniki, the Department of Microbiology, Medical School, National and Kapodistrian University of Athens and the Diagnostic Services Laboratory, Public Health Laboratories, Hellenic Pasteur Institute of Athens) in which the vast majority of suspected cases were tested and $99 \%$ of cases were diagnosed in 2018 .

Serum and CSF specimens were tested for the presence of WNV-specific IgM and IgG antibodies using commercial ELISA kits (Focus Technologies, Cypress, CA, United States). Reverse transcription (RT)-PCR tests (in house and commercial) were performed on RNA extracted from blood, CSF or urine samples. The National Reference Center for Arboviruses performed an RT-nested PCR, which amplifies a 520-bp fragment of the WNV non-structural protein 3 (NS3) gene on PCRpositive samples [38]. All PCR products were sequenced in a $3130 \mathrm{ABI}$ Genetic Analyzer (Applied Biosystems, Foster City, CA, US). Nucleotide sequences were aligned with similar sequences of the same genomic region retrieved from the GenBank database, and phylogenetic analysis was performed using the molecular evolutionary genetics analysis (MEGA)7 software [49]. The National Reference Center for Arboviruses performed also neutralisation tests in PCR-negative, IgG-positive serum samples and applied PCR combined with Sanger sequencing for the genetic characterisation of the strain(s); in addition, next generation sequencing was performed on selected samples.

\section{Blood safety measures}

Blood safety measures for the protection of blood donations against WNV infection were implemented nationwide for blood donors residing or having visited affected municipalities. These measures included blood donor deferral or screening of donated blood for WNV RNA, with targeted individual donation (ID) 


\section{FIGURE 1}

Number of laboratory diagnosed West Nile virus neuroinvasive disease cases by week of symptom onset, Greece, 2010-2018 $(\mathrm{n}=242)^{\mathrm{b}}$

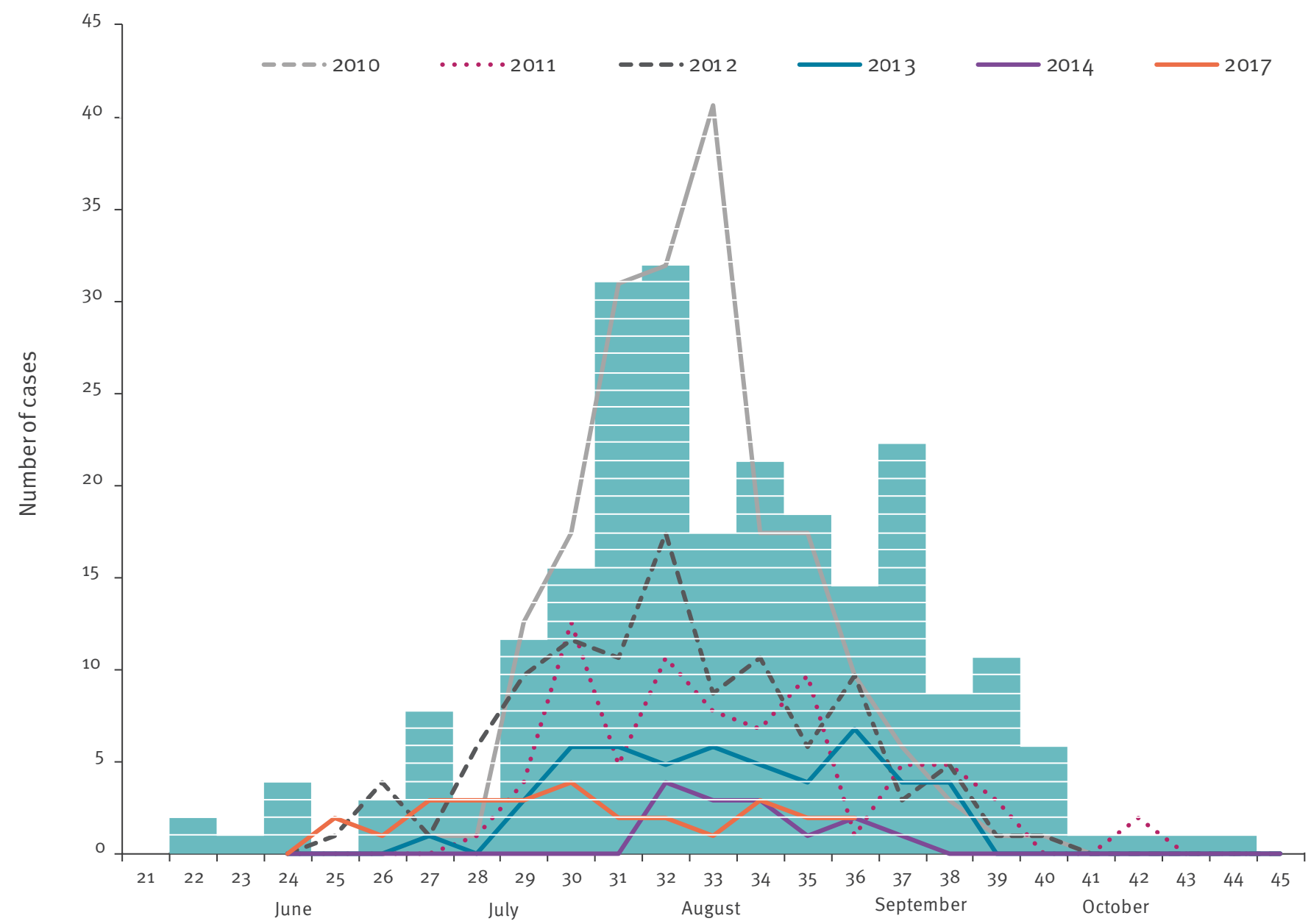

Week number and month of symptom onset

a In 2015 and 2016 no cases were recorded. Each box represents one WNND case diagnosed and reported in 2018.

${ }^{b}$ One WNND case with undetermined week of symptom onset is not included.

nucleic acid amplification testing (NAT), and haemovigilance (i.e. surveillance of serious adverse or unexpected events or reactions in donors or recipients, epidemiological follow-up of donors, as referred to in Article 4 and Annex III of the Commission Directive 2004/33/EC [50]).

\section{Data analysis}

We performed descriptive analysis of the surveillance data, i.e. geographical and temporal distribution of human cases with WNV infection, demographic characteristics (age, sex), clinical manifestations, underlying diseases and clinical outcome.

We assigned week numbers using the International Organization for Standardization (ISO) 8601 standard [51].

\section{Ethical statement}

No ethical approval was needed for this study, as no individual data were identifiable, and only aggregated data were analysed and presented.

\section{Results}

On week 26/2018, NPHO/former HCDCP was notified of the first six human WNV infection cases in the season, in Attica Region, with symptom onset on 31 May (week 22), and within the first fortnight of June. Cases continued to occur throughout the 2018 transmission period, in several areas of the country.

A total of 317 autochthonous cases of WNV infection were recorded in 2018 all over Greece, including 243 WNND cases, 68 WNF cases, and six asymptomatic cases (blood donors). The overall WNND incidence was 2.25 cases per 100,000 population; this was the highest incidence ever recorded in Greece, with a $23 \%$ statistical significant increase compared with 2010 


\section{FIGURE 2}

Incidence (per 100,000 population) of West Nile virus neuroinvasive disease by probable municipality of exposure, Greece, $2018(\mathrm{n}=242)^{\mathrm{a}}$

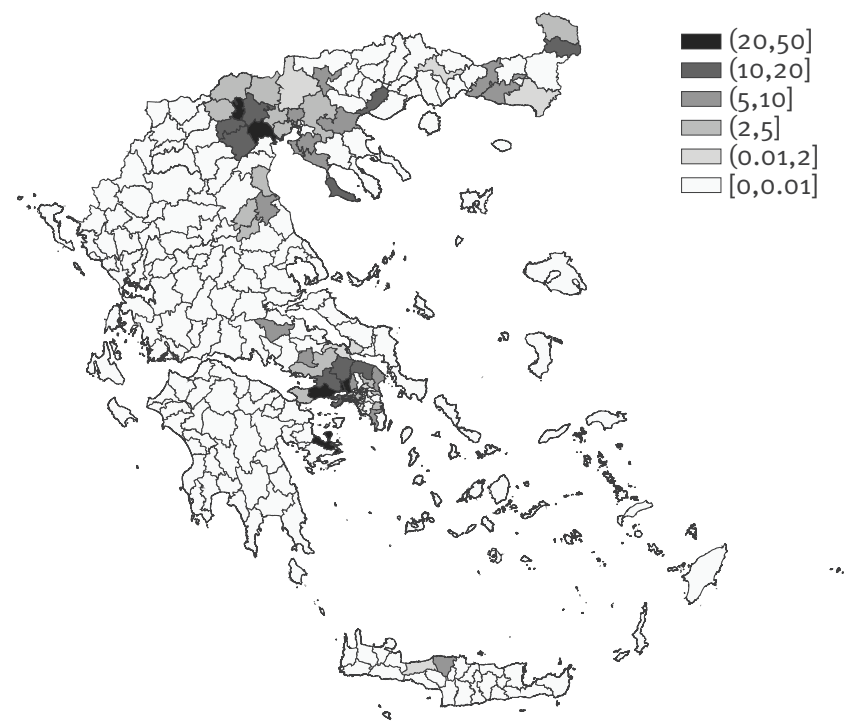

a For one case, the suspected municipality of exposure could not be determined.

$(p=0.03)$, the previous most intense season (Table 1 ). Two of the 317 reported WNV infection cases were diagnosed abroad, in Czech Republic and in Italy respectively. One more WNND case was classified as imported from Romania (not included in the current analysis).

Eleven cases of WNV infection were blood donors (aged 30-62 years old) diagnosed in affected areas; five of these cases developed symptoms and six remained asymptomatic.

In $2018,77 \%$ of cases presented with WNND, compared with a total of $71 \%(474 / 672)$ of cases diagnosed in the previous 2010-2017 period, ranging from 58\% in 2017 to $93 \%$ in 2014 (Table 1 ).

A total of $312(98 \%)$ cases of WNV infection (or their close relatives) were directly interviewed by NPHO/ former HCDCP. These included the exported case diagnosed in Italy, who was also investigated in collaboration with the Italian public health authorities. Four cases (or their relatives) diagnosed in Greece could not be directly contacted, and the exported case diagnosed in the Czech Republic was investigated by the Czech public health authorities. Close relatives of 235 (75\%) cases were interviewed.

For 10 cases of the 312 interviewed cases, the exact date of diagnosis in the laboratory was missing. For the remaining cases, these were investigated within a median period of 1 day (range: 0-29) after diagnosis; $74 \%(222 / 302)$ of cases were interviewed within 2 days after diagnosis, and 61\% (183/302) within 1 day.
All symptomatic cases $(n=311)$ had symptom onset within the 5 month period from 31 May 2018 (week 22/2018) to 29 October 2018 (week 44/2018), while the last date of positive blood sample was on 2 November 2018 from an asymptomatic blood donor. The number of recorded WNND cases peaked in weeks 31 and 32 (with 32 and 33 WNND cases per week, respectively).

Figure 1 shows the reported WNND cases by week of symptom onset in 2018, compared with previous seasons (2010-2017).

For three cases, the probable place of exposure could not be determined. The remaining WNV infection cases were exposed in a total of $86 / 325(26 \%)$ municipalities, $24 / 74(32 \%)$ regional units, and $7 / 13(54 \%)$ regions, indicating a wide geographical distribution of cases compared with previous transmission periods (Table 1 ).

The geographical distribution of WNND cases is presented in Figure 2. Two major epicentres were recorded, in the regions of Attica and Central Macedonia (Table 2, Figure 2), with the highest number of WNV infection and WNND cases ever recorded in Attica and the second highest number of cases ever recorded in Central Macedonia (since 2010) (Table 2).

Among the 24 regional units (nomenclature of territorial units for statistics (NUTS) 3 level) affected in 2018, 22 were affected at least once in previous seasons, and $98 \%(308 / 314)$ of cases occurred in regional units previously affected. Cases occurred both in rural and urban areas, and large cities were also affected, including the capital.

In June 2018, cases were recorded mainly from Attica (and a couple of cases from the nearby Sterea Ellada region). From July, cases were also recorded in Central Macedonia, and from August, in East Macedonia and Thrace region, in north-eastern Greece. In SeptemberOctober, cases were further recorded in Thessaly region. A couple of cases were also recorded in Crete and Peloponnese regions (Figure 3).

For cases of WNV infection with available information on their place of exposure, the vast majority $(87 \%$; 268/309) were infected in their place of permanent residence (the rest, mainly in the place of summer vacation).

The median age of the 243 WNND cases in 2018 was 75 years (range: 10-95years), significantly higher $(p=0.012)$ than the median age of the total 474 WNND cases diagnosed in the previous 2010-2017 period (72 years; range: 2-95). Among WNND cases, $81 \%$ $(196 / 243)$ were aged 60 years or older. The incidence of WNND cases increased from 0.14 per 100,000 population in the less than 20 year-olds to 10.66 per 100,000 population in those who were $\geq 80$ years old (Table 3 ). The age of WNND cases in 2018 (median age: 75 years; 
TABLE 2

Number of WNV infection cases and WNND cases per probable region of exposure and year, Greece, 2010-2018 $(\mathrm{n}=989$ WNV infection cases)

\begin{tabular}{|l|c|c|c|c|c|c|c|}
\hline \multirow{2}{*}{ Probable region of exposure } & \multicolumn{5}{|c|}{ Number of recorded WNV infection cases (number of WNND cases) per yeara } \\
\cline { 2 - 8 } & 2010 & 2011 & 2012 & 2013 & 2014 & 2017 & 2018 \\
\hline Attica & $0(0)$ & $30(21)$ & $45(30)$ & $35(24)$ & $2(2)$ & $0(0)$ & $160(136)$ \\
\hline Central Macedonia & $250(186)$ & $31(21)$ & $20(15)$ & $21(13)$ & $0(0)$ & $0(0)$ & $117(78)$ \\
\hline West Macedonia & $1(1)$ & $1(1)$ & $0(0)$ & $0(0)$ & $0(0)$ & $0(0)$ & $0(0)$ \\
\hline East Macedonia and Thrace & $1(1)$ & $0(0)$ & $76(46)$ & $27(11)$ & $11(10)$ & $0(0)$ & $14(11)$ \\
\hline Sterea Ellada & $0(0)$ & $6(6)$ & $1(1)$ & $0(0)$ & $0(0)$ & $0(0)$ & $10(7)$ \\
\hline Thessaly & $9(8)$ & $30(25)$ & $0(0)$ & $0(0)$ & $0(0)$ & $0(0)$ & $8(7)$ \\
\hline Peloponnese & $0(0)$ & $0(0)$ & $0(0)$ & $0(0)$ & $0(0)$ & $43(23)$ & $2(1)$ \\
\hline Crete & $0(0)$ & $0(0)$ & $0(0)$ & $0(0)$ & $0(0)$ & $1(1)$ & $2(2)$ \\
\hline West Greece & $1(1)$ & $1(1)$ & $8(7)$ & $1(1)$ & $2(2)$ & $4(4)$ & $0(0)$ \\
\hline Ionian islands & $0(0)$ & $0(0)$ & $4(4)$ & $1(1)$ & $0(0)$ & $0(0)$ & $0(0)$ \\
\hline North Aegean & $0(0)$ & $0(0)$ & $2(2)$ & $0(0)$ & $0(0)$ & $0(0)$ & $0(0)$ \\
\hline South Aegean & $0(0)$ & $1(0)$ & $0(0)$ & $0(0)$ & $0(0)$ & $0(0)$ & $0(0)$ \\
\hline Ipeiros & $0(0)$ & $0(0)$ & $1(1)$ & $0(0)$ & $0(0)$ & $0(0)$ & $0(0)$ \\
\hline Unknown/undetermined & $0(0)$ & $0(0)$ & $4(3)$ & $1(1)$ & $0(0)$ & $0(0)$ & $4(1)$ \\
\hline Total & $262(197)$ & $100(75)$ & $161(109)$ & $86(51)$ & $15(14)$ & $48(28)$ & $317(243)$ \\
\hline
\end{tabular}

WNND: West Nile virus neuroinvasive disease; WNV: West Nile virus.

${ }^{a}$ As no cases of WNV infection in Greece were recorded in 2015 and 2016, these years are not shown in the Table.

range: $10-95)$ was significantly higher $(p<0.001)$ than that of the diagnosed symptomatic WNF cases (median age: 65 years; range: $19-97)$.

Among the 317 WNV infection cases and the 243 WNND cases, $62 \%(n=198)$ and $65 \%(n=157)$ were male, respectively. The WNND incidence among males was almost two times higher than that among females ( $p<0.001)$ (Table 3).

The median period from symptom onset to diagnosis for 239 WNND cases with available relevant information was 11 days (range: $2-45$ ), as well as for 63 nonWNND cases, excluding blood donors (range: 3-57). The median period from admission to hospital to diagnosis for 295 cases of WNV infection was 6 days (range: 0-40).

Among the 243 WNND cases, 206 (85\%) had encephalitis/meningoencephalitis (including 11 patients also presenting AFP), $34(14 \%)$ cases had meningitis, and three cases had AFP signs only (Table 4).

A total of 311 (98\%) diagnosed WNV infection cases reported clinical symptoms, the most common being fever, followed by malaise/fatigue, confusion/consciousness level deterioration, anorexia, sleepiness, chills, headache, gastrointestinal symptoms (diarrhoea, nausea, vomiting, abdominal pain), dizziness, myalgia/arthralgia, extrapyramidal signs (tremor, parkinsonism), ataxia/gait disorders, rash, limb paralysis, numbness, retro-orbital pain, vision deterioration, lymph nodes enlargement (Table 5).
Among WNND cases, 83\% (201/242) reported at least one underlying chronic disease, including cardiovascular diseases $(62 \% ; 150 / 242$, including stroke and heart disease), heart disease $(60 \% ; 144 / 242$, including hypertension), hypertension ( $45 \% ; 110 / 242$ ), diabetes mellitus (31\%; 75/241), coronary heart disease (19\%; 45/242), chronic neuropsychiatric disease $(16 \%$; $39 / 242)$, arrhythmia (13\%; 32/242), cancer (13\%; $31 / 241)$, stroke $(9 \% ; 22 / 240)$, valvulopathy/heart failure $(7 \% ; 17 / 242)$, other immunosuppression than diabetes and cancer $(7 \% ; 16 / 242$, including autoimmune disorders, hepatic cirrhosis, organ transplant, myasthenia, corticosteroids treatment), thyroid disease (7\%; $18 / 242)$, chronic renal failure $(6 \% ; 14 / 242)$, respiratory disease $(4 \% ; 9 / 242)$, alcohol abuse $(1 \% ; 2 / 240)$.

Among the 311 symptomatic cases, $94 \%(n=291)$ were hospitalised: $99 \%(241 / 243)$ of the WNND cases and $74 \%(50 / 68)$ of the symptomatic non-WNND cases.

The median duration of hospitalisation of 239 hospitalised cases of WNV infection discharged from the hospital was 10 days (range: 1-102), while among 192 WNND cases (hospitalised and discharged from the hospital) it was 11 days (range: 2-102). Forty-eight cases were hospitalised in ICU: 47 with WNND, while the one with non-WNND had other co-morbidities. The median duration of hospitalisation in ICU (before discharge or fatal outcome) was 19 days (range: $1-237$ ).

A total of 51 deaths were recorded during hospitalisation, with an overall case fatality (CF) of $16 \%$ among all cases diagnosed with WNV infection. Among fatal cases, 48 had WNND, with a $20 \%$ CF among cases with WNND; similar with the total CF among cases 


\section{FIGURE 3}

Number of laboratory-diagnosed West Nile virus neuroinvasive disease cases by week of symptom onset and region of exposure, Greece, $2018(\mathrm{n}=241)^{\mathrm{a}}$

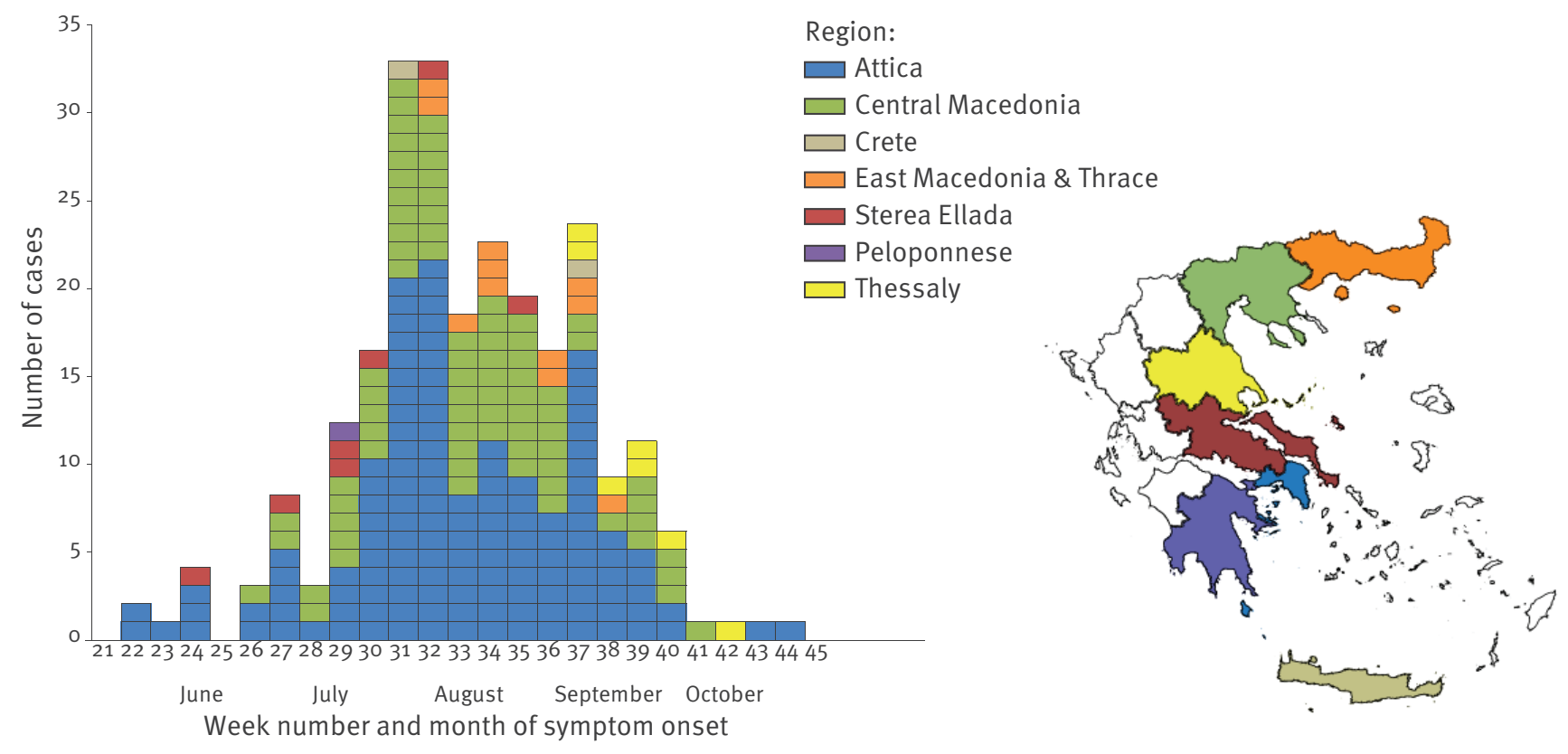

WNND: West Nile virus neuroinvasive disease.

a One WNND case with undetermined week of symptom onset and one WNND case with undetermined region of exposure (with symptom onset at week 32/2018) are not included.

with WNND observed during the 2010-2017 period $(81 / 474,17 \%)$ (Table 1$)$. The clinical presentation of WNND among fatal cases is described in Table 4. The CF of the encephalitis/meningo-encephalitis cases was $22 \%(45 / 206)$, whereas it was $9 \%(3 / 34)$ among meningitis cases. The median age of fatal cases was 79 years (range: 63-97). The median period from symptom onset to death (during hospitalisation) was 21 days (range: 6-243).

The vast majority of patients $(67 \% ; 204 / 306)$ were retired, 38\%(117/308) reported doing agricultural or gardening activities, and $22 \%(67 / 306)$ reported having a routine outdoor activity after dawn.

National and regional public health authorities were informed about diagnosed cases and their probable place of exposure, within a few hours after their investigation, and within 24 hours after their diagnosis, via confidential emails.

\section{Laboratory results}

Of the 317 cases, 198 (62\%) were confirmed, either by WNV-specific IgM antibody response in CSF $(n=124)$, and/or positive PCR in any sample $(n=77)$ (in blood, and/or CSF, and/or urine), and/or by WNV-specific IgM and IgG antibody response in serum and confirmation by neutralisation $(n=29)$. A total of 97 cases were confirmed by IgM antibody response in CSF only, 50 cases were confirmed by positive PCR in any sample only, 20 cases were confirmed by neutralisation only, and 31 cases were confirmed by more than one confirmatory methods.

A total of 119 cases were considered as probable, since the diagnosis was based only on the detection of WNVspecific IgM antibodies in serum.

In all but one of the 15 sequenced samples, the sequences clustered into the Central European/ Hungarian subclade of WNV lineage 2, similar to the strain of the 2010 outbreak (Nea-Santa-Greece-2010 strain). One sequence taken from a case in Thrace region (northern-eastern Greece) clustered within the Eastern European/Russian subclade of WNV lineage 2 (Figure 4) [52].

In total, among the cases tested, 99.6\%(275/276) had WNV-specific IgM antibodies in serum and 95\% (124/131) had WNV-specific IgM antibody response in CSF. In 29 cases with positive IgM and IgG antibodies in serum, the diagnosis was confirmed by neutralisation. A total of 52 cases had positive PCR in blood, 37 cases had positive PCR in urine (in 10 of which this was the method of confirmation), and eight cases had positive PCR in CSF. The median time from symptom onset to sampling for the cases with positive PCR in blood was 6 days (range: -3 to 23), for the cases with positive PCR in urine 6 days (range: $2-20$ ) and for cases with positive PCR in CSF 9 days (range: $1-20$ ). 
TABLE 3

Age and sex distribution of West Nile virus neuroinvasive disease cases, Greece, $2018(\mathrm{n}=243)$

\begin{tabular}{|c|c|c|c|}
\hline Characteristics & Number of cases & Incidence rate (per 100,000 population)a & Risk ratio ( $95 \%$ confidence interval) \\
\hline \multicolumn{4}{|c|}{ Age group (in years) } \\
\hline$<20$ & 3 & 0.14 & Reference \\
\hline $20-29$ & 3 & 0.27 & $1.85(0.37-9.15)$ \\
\hline $30-39$ & 13 & 0.92 & $6.38(1.82-22.38)$ \\
\hline $40-49$ & 11 & 0.68 & $4.73(1.32-16.95)$ \\
\hline $50-59$ & 17 & 1.15 & $7.97(2.34-27.21)$ \\
\hline $60-69$ & 35 & 2.76 & $19.21(5.91-62.46)$ \\
\hline $70-79$ & 82 & 8.28 & $57.62(18.21-182.37)$ \\
\hline$\geq 80$ & 79 & 10.66 & $74.22(23.43-235.09)$ \\
\hline \multicolumn{4}{|l|}{ Sex } \\
\hline Female & 86 & 1.55 & Reference \\
\hline Male & 157 & 3.01 & $1.94(1.49-2.52)$ \\
\hline
\end{tabular}

a Population data from Hellenic Statistical Authority (EL.STAT.) [63].

\section{TABLE 4}

Number and percentage of WNND cases $(n=243)$ as well as number and percentage of fatal cases with WNND ( $\mathrm{n}=48$ ), by clinical presentation, Greece, 2018

\begin{tabular}{|c|c|c|c|c|c|}
\hline Parameter & Encephalitis & $\begin{array}{c}\text { Meningo } \\
\text {-encephalitis }\end{array}$ & Meningitis & $\begin{array}{l}\text { AFP } \\
\text { only }\end{array}$ & $\begin{array}{c}\text { AFP and } \\
\text { encephalitis/ } \\
\text { meningitis }\end{array}$ \\
\hline Number of WNND cases & 128 & 78 & 34 & 3 & 11 \\
\hline Percentage of total WNND cases & $53 \%$ & $32 \%$ & $14 \%$ & $1 \%$ & $5 \%$ \\
\hline Number of fatal cases with WNND & 31 & 14 & 3 & 0 & 3 \\
\hline Percentage of fatal cases among total WNND fatal cases & $65 \%$ & $29 \%$ & $6 \%$ & NA & $10 \%$ \\
\hline
\end{tabular}

AFP: acute flaccid paralysis; NA: not applicable; WNND: West Nile virus neuroinvasive disease.

In each row where numbers of cases are presented, the sum of the cases in the respective row can be more than the total number of cases, as a given case could have more than one presentation.

\section{Discussion}

WNV infections show a strong seasonal pattern in Europe, with the first human cases usually observed in June and most cases recorded from July to October [9]. Accordingly, from 2010 to 2017, human cases of WNV infection in Greece were recorded from the end of June until the beginning of October. In contrast, the onset of symptoms in the first recorded human case in 2018 was in week 22 (end of May), making this the earliest WNV transmission season ever noted in the country and in Europe. The seasonal outbreak moreover lasted until early November (Figure 1) and coincided with the longest season (i.e. more than 5 months) in the last years in Europe [9], suggesting a possible need to widen the surveillance period.

The number of recorded WNND cases in Greece in 2018 peaked in weeks 31 and 32 and remained at over 15 per week, from week 30 to week37. The numbers of total WNV infections and WNND cases were also respectively the highest recorded since the emergence of the virus in the country in 2010. Moreover, the 2018 WNND cases accounted for more than a third of the total number of such cases recorded since 2010 (34\%, 243/717). This suggests a more intense seasonal virus circulation during 2018. In this regard, large outbreaks occurred in other central European and Mediterranean countries simultaneous to the 2018 WNV seasonal outbreak in Greece [53].

The increased number of cases diagnosed in Greece in 2018 compared with previous years cannot be attributed to a higher sensitivity of the surveillance system, as enhanced surveillance has been consistently implemented in the country during each transmission season since 2010 . This has included raising awareness of physicians on an annual basis, publishing updated weekly surveillance reports and providing free-ofcharge diagnosis. The large number of WNF cases diagnosed in 2018 ( $22 \%$ of the total symptomatic cases), and in previous years (Table 1), further indicates the enhanced awareness of physicians.

In 2018, the case definition was expanded to include asymptomatic cases detected during blood screening in affected areas; however, this change did not crucially affect the overall amount of recorded WNV infections, given the small number of diagnosed asymptomatic cases $(n=6)$. Either way, the number of WNND cases (which describes the burden more accurately and is 
TABLE 5

Symptoms ${ }^{\mathrm{a}}$ of West Nile virus neuroinvasive disease cases $(\mathrm{n}=243)$ and West Nile fever cases $(\mathrm{n}=68)$, Greece, 2018

\begin{tabular}{|c|c|c|c|c|}
\hline \multirow[b]{2}{*}{ Symptom } & \multicolumn{2}{|c|}{ WNND cases } & \multicolumn{2}{|c|}{ WNF cases } \\
\hline & $\begin{array}{l}\text { Proportion }{ }^{\mathrm{b}} \text { with the } \\
\text { symptom }\end{array}$ & Percentage & $\begin{array}{l}\text { Proportion }{ }^{\mathrm{b}} \text { with the } \\
\text { symptom }\end{array}$ & Percentage \\
\hline Fever & $240 / 242$ & 99 & $65 / 68$ & 96 \\
\hline Malaise/fatigue & $212 / 231$ & 92 & $60 / 67$ & 90 \\
\hline Confusion consciousness level deterioration & $179 / 232$ & 77 & $13 / 67$ & 19 \\
\hline Anorexia & $139 / 189$ & 74 & $44 / 64$ & 69 \\
\hline Sleepiness & $159 / 219$ & 73 & $17 / 62$ & 27 \\
\hline Chills & $136 / 201$ & 68 & $30 / 62$ & 48 \\
\hline Headache & $129 / 227$ & 57 & $42 / 68$ & 62 \\
\hline $\begin{array}{l}\text { At least one gastrointestinal symptom (i.e., diarrhoea, } \\
\text { nausea, vomiting, abdominal pain) }\end{array}$ & $134 / 237$ & 57 & $39 / 66$ & 59 \\
\hline Dizziness & $103 / 207$ & 50 & $18 / 64$ & 28 \\
\hline Myalgia/arthralgia & $94 / 221$ & 43 & $30 / 67$ & 45 \\
\hline Vomiting & $90 / 238$ & 38 & $20 / 67$ & 30 \\
\hline Extrapyramidal signs (tremor, parkinsonism) & $77 / 207$ & 37 & $0 / 66$ & NA \\
\hline Ataxia, gait disorders & $47 / 150$ & 31 & $0 / 64$ & NA \\
\hline Diarrhoea & $50 / 237$ & 21 & $18 / 66$ & 27 \\
\hline Nausea & $47 / 237$ & 20 & $18 / 67$ & 27 \\
\hline Rash & $39 / 235$ & 17 & $15 / 67$ & 22 \\
\hline Abdominal pain & $33 / 223$ & 15 & $7 / 66$ & 11 \\
\hline Limb paralysis & $24 / 213$ & 11 & $0 / 66$ & NA \\
\hline Numbness & $15 / 155$ & 10 & $3 / 57$ & 5 \\
\hline Retro-orbital pain & $17 / 181$ & 9 & $9 / 62$ & 15 \\
\hline Vision deterioration & $11 / 183$ & 6 & $1 / 64$ & 2 \\
\hline Lymph nodes enlargement & $3 / 66$ & 5 & $5 / 32$ & 16 \\
\hline
\end{tabular}

CKP: creatine phosphokinase; NA: not applicable; SIADH: syndrome of inappropriate antidiuretic hormone secretion; WNF: West Nile fever; WNND: West Nile virus neuroinvasive disease.

a Other symptoms/signs reported from the treating physicians included: acute respiratory failure $(n=22)$, bradypsychismus $(n=16)$, seizures $(n=15)$, respiratory infection $(n=13)$, dysarthria-speech disorders $(n=12)$, acute renal failure $(n=10)$, diplopia $(n=9)$, myoclonous $(n=9)$, aphasia/apraxia $(n=8)$, arrhythmia $(n=5)$, cough $(n=5)$, hepatitis/liver dysfunction $(n=5)$, rhabdomyolysis/increased CPK $(n=5)$, SIADH/ hyponatraemia $(n=5)$, biphasic fever $(n=4)$, pulmonary oedema $(n=4)$, sore throat $(n=4)$, chorea/ ballistic movements $(n=3)$, dysautonomia $(n=3)$, hearing disorders $(n=3)$, myocarditis/increased troponine $(n=3)$, pulmonary embolism $(n=3)$, hypokalaemia $(n=2)$, acute epiglottitis $(n=1)$, aneurysm rupture $(n=1)$, blepharoptosis $(n=1)$, Guillain-Barré syndrome $(n=1)$, retinitis $(n=1)$ and uveitis $(n=1)$,

${ }^{b}$ Number of cases with the symptom in question/number of cases with known information.

usually preferred for comparisons) was also the largest ever recorded in Greece.

The higher case fatality for WNND cases in Greece compared with that in other European countries [9] could be at least partly attributed to the fact that the Greek surveillance system records all fatalities during the whole hospitalisation period of the patients, which may last for several months (as cases are actively followed up on a daily basis). Furthermore, all deaths of patients with WNV infection are included in the count of fatalities even when they are not directly attributed to WNV infection.

Climatic conditions (mild winter, high temperatures in spring and early summer, as well as rainfall with flooding in the summer), may have contributed to an early and intense WNV circulation in 2018 in Europe $[53,54]$. The year 2018 was one of the warmest years on record for Europe, with a period of particularly warm weather beginning in late spring, and summer. In most of the years of the 21th century, the average temperatures remained higher than the 1981-2010 average, and years with a long duration of positive anomalies were not unusual; however, 2018 was a notable year with much larger anomalies. In addition, the southeast of Europe experienced an unseasonably wet summer in 2018, ranking among the sixth wettest since 1950 [55]. According to the Hellenic National Meteorological Service, above average temperatures were also recorded in mainland Greece during spring 2018 , with the hottest April ever recorded since 1960 in many areas of the country. Temperatures in May 2018 were also higher than the 1971-2000 average in WNV affected areas. In June and July 2018, unusually high precipitations were recorded, with a rainfall increase of more than $200 \%$ above the normal values (1971-2000), almost nationwide, which resulted in flooding in several areas, including areas of both Central Macedonia and Attica regions (the 2018 WNV epicentres) [56].

In terms of geographical spread, the first WNV infection outbreak in Greece in 2010 was recorded in the region of Central Macedonia, northern Greece [57]. In the following years, the virus spread further north-east 


\section{FIGURE 4}

Phylogenetic analysis of West Nile virus strains detected in Greece in 2018

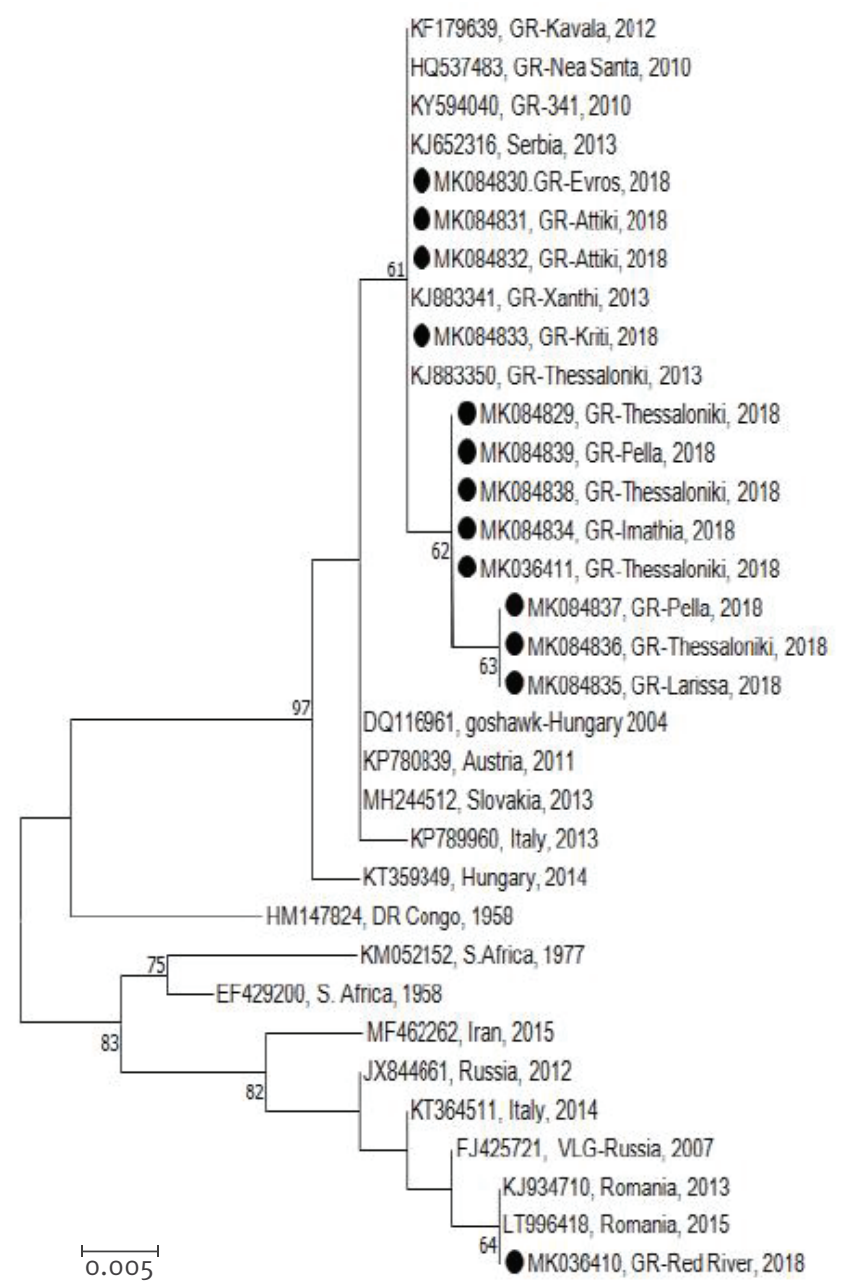

NS3: non-structural protein 3.

Neighbour-Joining phylogenetic tree based on 328-bp fragment of West Nile virus NS3 gene. The evolutionary distances were computed using the Kimura 2-parameter method. The tree is drawn to scale, with branch lengths measured in the number of substitutions per site. The percentage of replicate trees in which the associated taxa clustered together in the bootstrap test $(1,000$ replicates) is shown next to the branches. Bootstrap values lower than $60 \%$ are not shown. Sequences in the trees are identifiable by GenBank accession number, country and year of isolation. Sequences of the present study are marked.

While 15 sequences from the 2018 outbreak were obtained, two sequences were slightly shorter than the rest, and they were not included in the phylogenetic tree.

as well as southwards, affecting also the Attica Region. In 2014 , only a few cases were diagnosed in the whole country, while no case was reported in 2015-2016. Human cases were recorded again in 2017, limited to a new geographical area, in Peloponnese, southern Greece. The limited number/absence of cases recorded in some seasons in previously highly affected areas might be partially attributed to acquired long-term immunity of local bird populations which diminished the virus circulation $[58,59]$.
In 2018 , the geographical distribution of human cases was widely spread, with more areas affected compared with previous years, indicating a nationwide circulation from south to north. The two main epicentres were Central Macedonia, the epicentre of the first recorded outbreak in Greece in 2010, and Attica, an epicentre of the 2011-2013 seasonal outbreaks. In the 2018 season, both rural and urban areas were affected, including large cities, in contrast to the first WNV outbreaks in Greece, which occurred mainly in rural areas.

WNV lineage 2 of the Central European/Hungarian subclade, which is observed in Greece since 2010, was repeatedly detected in all regions, suggesting the establishment of this lineage in Greece. A recent study based on evolutionary dynamics of lineage 2 WNV based on whole genome sequences showed that three novel, independent introductions from Hungary and Bulgaria caused the 2018 seasonal outbreak of WNV in northern Greece [6o]. It is of interest that a strain of the Eastern European/Russian subclade of WNV lineage 2 was detected in a case in north-eastern Greece, indicating a new strain introduction. This was not unexpected, given the geographical location of Greece at the crossroads of three continents and the plethora of wetlands in the specific area of northern Greece, where a wide variety of migratory birds stop, with the potential to spread pathogens - while infectious - at the local level.

WNV has become endemic in Greece, as in several neighbouring and other European countries [8,9]. Despite the large number of cases diagnosed on a daily basis, enhanced surveillance of human cases was continuously performed with a timely case investigation and identification of the probable place of infection. The established enhanced surveillance system, and the timely communication and awareness of clinicians and public health professionals, combined with the high level of laboratory response, are vital for the early detection of human cases and the prompt implementation of response measures (vector control, communication, blood safety measures). Timeliness is of major importance, as the early detection of cases and identification of the affected areas is crucial for reducing the spread of WNV and other VBD.

Vector and animal surveillance are also considered useful for the early identification and the geographical characterisation of the WNV circulation, in order to guide response measures [31,61]. According to the national programme for the WNV surveillance in animals in Greece, WNV surveillance in equids and wild birds is planned, organised and coordinated during the transmission season, on an annual basis by the national animal health authorities. Information is shared on a daily basis between public health and animal health national authorities.

Following the severe WNV transmission season in 2018, an After Action Review was performed in Greece 
(as well as in three other countries, Italy, Serbia and Slovenia) organised by the European Centre for Disease Prevention and Control. This included stakeholders from national, regional and local levels, in order to identify best practices, lessons learned, preparedness gaps and areas for improvement [62]. Enhanced surveillance and diagnostic capacity, strong commitment of involved stakeholders and inter-sectoral collaboration in the context of One Health (national committees, working groups) were identified as strong points. Resources, jurisdictions, procurement design and One Health coordination strategy were identified as areas needing further improvement. The evaluation of effectiveness and impact of vector control measures and biocides use was also highlighted as a priority area to guide targeted interventions and improve preparedness and response.

\section{Acknowledgements}

The contribution of physicians, laboratory staff, and public health professionals of the Regional Public Health authorities to the enhanced surveillance of WNV infection is highly appreciated. In addition, we would like to specially thank Anthi Chrysostomou, Theologia Sideroglou, Anastasia Andreopoulou, Androniki Ntakou and Gregory Varvaresos for their support in the surveillance activities and the investigation of the cases.

\section{Conflict of interest}

None declared.

\section{Authors' contributions}

Danai Pervanidou, Annita Vakali, Theano Georgakopoulou, Sotirios Tsiodras, Takis Panagiotopoulos, Eleni Patsoula, George Koliopoulos, Constantina Politis, Kostas Stamoulis, Christos Hadjichristodoulou contributed to risk assessment, surveillance and response activities.

Danai Pervanidou, Annita Vakali, Christos Hadjichristodoulou, Sotirios Tsiodras and Anna Papa conducted the analysis and wrote the first draft of this manuscript.

Elpida Gavana, Styliani Pappa, Maria Mavrouli, Maria Emmanouil, George Sourvinos, Andreas Mentis, Athanassios Tsakris and Anna Papa provided the laboratory data of the human cases.

Constantina Politis and Kostas Stamoulis provided the haemovigilance findings and data on surveillance in the blood donor population.

All authors read and critically revised the first as well as the subsequent drafts of this manuscript and approved the final version.

\section{References}

1. Petersen LR, Brault AC, Nasci RS. West Nile virus: review of the literature. JAMA. 2013;310(3):308-15. https://doi.org/10.1001/ jama.2013.8042 PMID: 23860989

2. Bowen RA, Nemeth NM. Experimental infections with West Nile virus. Curr Opin Infect Dis. 2007;20(3):293-7. https://doi. org/10.1097/QCO.obo13e32816b5cad PMID: 17471040

3. Colpitts TM, Conway MJ, Montgomery RR, Fikrig E. West Nile Virus: biology, transmission, and human infection. Clin Microbiol Rev. 2012;25(4):635-48. https://doi.org/10.1128/ CMR.00045-12 PMID: 23034323

4. Hayes EB, Komar N, Nasci RS, Montgomery SP, O'Leary DR, Campbell GL. Epidemiology and transmission dynamics of West Nile virus disease. Emerg Infect Dis. 2005;11(8):1167-73. https://doi.org/10.3201/eid1108.050289a PMID: 16102302

5. Kramer LD, Li J, Shi PY. West Nile virus. Lancet Neurol. 2007;6(2):171-81. https://doi.org/10.1016/S14744422(07)70030-3 PMID: 17239804

6. Sambri V, Capobianchi M, Charrel R, Fyodorova M, Gaibani $P$, Gould E, et al. West Nile virus in Europe: emergence, epidemiology, diagnosis, treatment, and prevention. Clin Microbiol Infect. 2013;19(8):699-704. https://doi. org/10.1111/1469-0691.12211 PMID: 23594175

7. Lim SM, Koraka P, Osterhaus AD, Martina BE. West Nile virus: immunity and pathogenesis. Viruses. 2011;3(6):811-28. https://doi.org/10.3390/v3060811 PMID: 21994755

8. European Centre for Disease Prevention and Control (ECDC). Factsheet about West Nile virus infection Stockholm: ECDC; 29 Nov 2018. Available from: https://www.ecdc.europa.eu/en/ west-nile-fever/facts/factsheet-about-west-nile-fever

9. European Centre for Disease Prevention and Control $(E C D C)$. West Nile virus infection. Annual epidemiological report for 2018. Stockholm: ECDC; 2019. Available from: https://www.ecdc.europa.eu/en/publications-data/ west-nile-virus-infection-annual-epidemiological-report-2018

10. Hubálek Z, Halouzka J. West Nile fever--a reemerging mosquitoborne viral disease in Europe. Emerg Infect Dis. 1999;5(5):64350. https://doi.org/10.3201/eido505.990505 PMID: 10511520

11. Rappole JH, Hubálek Z. Migratory birds and West Nile virus. J Appl Microbiol. 2003;94(s1) Suppl;47S-58S. https://doi. org/10.1046/j.1365-2672.94.S1.6.x PMID: 12675936

12. Rappole JH, Derrickson SR, Hubálek Z. Migratory birds and spread of West Nile virus in the Western Hemisphere. Emers Infect Dis. 2000;6(4):319-28. https://doi.org/10.3201/ eid0604.000401 PMID: 10905964

13. Reed KD, Meece JK, Henkel JS, Shukla SK. Birds, migration and emerging zoonoses: west nile virus, lyme disease, influenza A and enteropathogens. Clin Med Res. 2003;1(1):5-12. https:// doi.org/10.3121/cmr.1.1.5 PMID: 15931279

14. Owen J, Moore F, Panella N, Edwards E, Bru R, Hughes M, et al. Migrating Birds as Dispersal Vehicles for West Nile Virus. EcoHealth. 2006;3(2):79-85. https://doi.org/10.1007/ S10393-006-0025-9

15. Gale P, Johnson N. Chapter 7 - The Role of Birds in the Spread of West Nile Virus. In: Johnson N, editor. The Role of Animals in Emerging Viral Diseases. Boston: Academic Press; 2014. p. $143-67$.

16. Bakonyi T, Ivanics E, Erdélyi K, Ursu K, Ferenczi E, Weissenböck $\mathrm{H}$, et al. Lineage 1 and 2 strains of encephalitic West Nile virus, central Europe. Emerg Infect Dis. 2006;12(4):618-23. https:// doi.org/10.3201/eid1204.051379 PMID: 16704810

17. Calistri P, Giovannini A, Hubalek Z, Ionescu A, Monaco F, Savini G, et al. Epidemiology of west nile in europe and in the mediterranean basin. Open Virol J. 2010;4(1):29-37. https:// doi.org/10.2174/1874357901004010029 PMID: 20517490

18. Di Sabatino D, Bruno R, Sauro F, Danzetta ML, Cito F, lannetti $\mathrm{S}$, et al. Epidemiology of West Nile disease in Europe and in the Mediterranean Basin from 2009 to 2013 . BioMed Res Int. 2014;2014:907852. https://doi.org/10.1155/2014/907852 PMID: 25302311

19. Rudolf I, Betášová L, Blažejová H, Venclíková K, Straková P, Sebesta 0, et al. West Nile virus in overwintering mosquitoes, central Europe. Parasit Vectors. 2017:10(1):452. https://doi. org/10.1186/s13071-017-2399-7 PMID: 28969685

20. Zeller HG, Schuffenecker I. West Nile virus: an overview of its spread in Europe and the Mediterranean basin in contrast to its spread in the Americas. Eur J Clin Microbiol Infect Dis. 2004;23(3):147-56. https://doi.org/10.1007/s10096-003-10851 PMID: 14986160

21. Chaskopoulou A, L’Ambert G, Petric D, Bellini R, Zgomba $M$, Groen TA, et al. Ecology of West Nile virus across fou European countries: review of weather profiles, vector population dynamics and vector control response. Parasit 
Vectors. 2016;9(1):482. https://doi.org/10.1186/s13071-0161736-6 PMID: 27590848

22. Rizzo C, Napoli C, Venturi G, Pupella S, Lombardini L, Calistri P, et al. , Italian WNV surveillance working group. West Nile virus transmission: results from the integrated surveillance system in Italy, 2008 to 2015. Euro Surveill. 2016;21(37):30340. https://doi.org/10.2807/1560-7917.ES.2016.21.37.30340 PMID: 27684046

23. Petrović T, Blázquez AB, Lupulović D, Lazić G, EscribanoRomero E, Fabijan D, et al. Monitoring West Nile virus (WNV) infection in wild birds in Serbia during 2012: first isolation and characterisation of WNV strains from Serbia. Euro Surveill. 2013;18(44):20622. https://doi.org/10.2807/1560-7917. ES2013.18.44.20622 PMID: 24176657

24. Bakonyi T, Ferenczi E, Erdélyi K, Kutasi O, Csörgő T, Seidel B, et al. Explosive spread of a neuroinvasive lineage 2 West Nile virus in Central Europe, 2008/2009. Vet Microbiol. 2013;165(12):61-70. https://doi.org/10.1016/j.vetmic.2013.03.005 PMID: 23570864

25. Papa A, Xanthopoulou K, Gewehr S, Mourelatos S. Detection of West Nile virus lineage 2 in mosquitoes during a human outbreak in Greece. Clin Microbiol Infect. 2011;17(8):1176 80. https://doi.org/10.1111/j.1469-0691.2010.03438.x PMID: 21781205

26. Zehender G, Veo C, Ebranati E, Carta V, Rovida F, Percivalle $\mathrm{E}$, et al. Reconstructing the recent West Nile virus lineage 2 epidemic in Europe and Italy using discrete and continuous phylogeography. PLoS One. 2017;12(7):e0179679. https://doi. org/10.1371/journal.pone.0179679 PMID: 28678837

27. Haussig JM, Young JJ, Gossner CM, Mezei E, Bella A, Sirbu A, et al. Early start of the West Nile fever transmission season 2018 in Europe. Euro Surveill. 2018;23(32):1800428. https:// doi.org/10.2807/1560-7917.ES.2018.23.32.1800428 PMID: 30107869

28. European Centre for Disease Prevention and Control (ECDC). West Nile virus infection. Stockholm: ECDC. [Accessed: 20 Jan 2020]. Available from: https://www.ecdc.europa.eu/en/ west-nile-virus-infection

29. Danis K, Papa A, Theocharopoulos G, Dougas G, Athanasiou M, Detsis $M$, et al. Outbreak of West Nile virus infection in Greece, 2010. Emerg Infect Dis. 2011;17(10):1868-72. https://doi. org/10.3201/eid1710.110525 PMID: 22000357

30. Papa A, Danis K, Baka A, Bakas A, Dougas G, Lytras T, et al. Ongoing outbreak of West Nile virus infections in humans in Greece, July-August 2010. Euro Surveill. 2010;15(34):19644. https://doi.org/10.2807/ese.15·34.19644-en PMID: 20807489

31. Gossner CM, Marrama L, Carson M, Allerberger F, Calistri $P$, Dilaveris D, et al. West Nile virus surveillance in Europe: moving towards an integrated animal-human-vector approach. Euro Surveill. 2017;22(18):30526. https://doi. org/10.2807/1560-7917.ES.2017.22.18.30526 PMID: 28494844

32. National Public Health Organization (NPHO). West Nile Virus infection, Annual epidemiological data 2010, 2011, 2012, 2013, 2014, 2017. Available from: https://eody.gov.gr/en/ epidemiological-statistical-data/annual-epidemiological-data/

33. Danis K, Papa A, Papanikolaou E, Dougas G, Terzaki I, Baka A, et al. Ongoing outbreak of West Nile virus infection in humans, Greece, July to August 2011. Euro Surveill. 2011;16(34):19951. PMID: 21903037

34. Pervanidou D, Detsis M, Danis K, Mellou K, Papanikolaou E, Terzaki I, et al. West Nile virus outbreak in humans, Greece, 2012: third consecutive year of local transmission. Euro Surveill. 2014;19(13):20758. https://doi.org/10.2807/15607917.ES2014.19.13.20758 PMID: 24721540

35. Mavrouli M, Vrioni G, Kapsimali V, Tsiamis C, Mavroulis S, Pervanidou D, et al. Reemergence of West Nile Virus Infections in Southern Greece, 2017. Am J Trop Med Hyg. 2019;100(2):4206. https://doi.org/10.4269/ajtmh.18-0339 PMID: 30526732

36. Papa A, Papadopoulou E, Gavana E, Kalaitzopoulou S, Mourelatos S. Detection of West Nile virus lineage 2 in Culex mosquitoes, Greece, 2012. Vector Borne Zoonotic Dis. 2013;13(9):682-4. https://doi.org/10.1089/vbz.2012.1212 PMID: 23697769

37. Papa A, Bakonyi T, Xanthopoulou K, Vázquez A, Tenorio A, Nowotny N. Genetic characterization of West Nile virus lineage 2, Greece, 2010. Emerg Infect Dis. 2011;17(5):920-2. https:// doi.org/10.3201/eid1705.101759 PMID: 21529413

38. Papa A, Politis C, Tsoukala A, Eglezou A, Bakaloudi V, Hatzitaki $M$, et al. West Nile virus lineage 2 from blood donor, Greece. Emerg Infect Dis. 2012;18(4):688-9. https://doi.org/10.3201/ eid1804.110771 PMID: 22469502

39. Papa A, Xanthopoulou K, Tsioka A, Kalaitzopoulou S, Mourelatos S. West Nile virus in mosquitoes in Greece. Parasitol Res. 2013;112(4):1551-5. https://doi.org/10.1007/ s00436-013-3302-x PMID: 23371497
40. Barzon L, Papa A, Pacenti M, Franchin E, Lavezzo E, Squarzon $L$, et al. Genome sequencing of West Nile Virus from human cases in Greece, 2012. Viruses. 2013;5(9):2311-9. https://doi org/10.3390/v5092311 PMID: 24064795

41. Papa A, Testa T, Papadopoulou E. Detection of West Nile virus lineage 2 in the urine of acute human infections. J Med Virol. 2014;86(12):2142-5. https://doi.org/10.1002/jmv.23949 PMID: 24760617

42. Papa A, Papadopoulou E, Kalaitzopoulou S, Tsioka K, Mourelatos S. Detection of West Nile virus and insect-specific flavivirus RNA in Culex mosquitoes, central Macedonia, Greece. Trans R Soc Trop Med Hyg. 2014;108(9):555-9. https:// doi.org/10.1093/trstmh/tru100 PMID: 25033823

43. Barzon L, Papa A, Lavezzo E, Franchin E, Pacenti M, Sinigaglia $A$, et al. Phylogenetic characterization of Central/Southern European lineage 2 West Nile virus: analysis of human outbreaks in Italy and Greece, 2013-2014. Clin Microbiol Infect. 2015;21(12):1122.e1-10. https://doi.org/10.1016/j. cmi.2015.07.018 PMID: 26235197

44. Mavridis K, Fotakis EA, Kioulos I, Mpellou S, Konstantas S, Varela E, et al. Detection of West Nile Virus - Lineage 2 in Culex pipiens mosquitoes, associated with disease outbreak in Greece, 2017. Acta Trop. 2018;182:64-8. https://doi. org/10.1016/j.actatropica.2018.02.024 PMID: 29474832

45. Bouzalas IG, Diakakis N, Chaintoutis SC, Brellou GD, Papanastassopoulou M, Danis K, et al. Emergence of Equine West Nile Encephalitis in Central Macedonia, Greece, 2010. Transbound Emerg Dis. 2016;63(6):e219-27. https://doi. org/10.1111/tbed.12334 PMID: 25660661

46. Valiakos G, Papaspyropoulos K, Giannakopoulos A, Birtsas P, Tsiodras S, Hutchings MR, et al. Use of wild bird surveillance, human case data and GIS spatial analysis for predicting spatial distributions of West Nile virus in Greece. PLoS One. 2014;9(5):e96935. https://doi.org/10.1371/journal. pone.0096935 PMID: 24806216

47. Valiakos G, Touloudi A, Iacovakis C, Athanasiou L, Birtsas P, Spyrou V, et al. Molecular detection and phylogenetic analysis of West Nile virus lineage 2 in sedentary wild birds (Eurasian magpie), Greece, 2010. Euro Surveill. 2011;16(18):19862. PMID: 21586266

48. European Commission. Commission Decision of $28 / \mathrm{IV} / 2008$ amending Decision 2002/253/EC laying down case definitions for reporting communicable diseases to the Community network under Decision No 2119/98/EC of the European Parliament and of the Council. Official Journal of the European Union. Luxembourg: Publications Office of the European Union. 18.06.2008:L 159. Available from: https://eur-lex.europa.eu/ legal-content/EN/TXT/PDF/?uri=0J:L:2008:159:FULL\&from=EN

49. Kumar S, Stecher G, Tamura K. MEGA7: Molecular Evolutionary Genetics Analysis Version 7.0 for Bigger Datasets. Mol Biol Evol. 2016;33(7):1870-4. https://doi.org/10.1093/molbev/ msw054 PMID: 27004904

50. Commission Directive. 2004/33/EC of 22 March 2004 implementing Directive 2002/98/EC of the European Parliament and of the Council as regards certain technical requirements for blood and blood components. Official Journal of the European Union Luxembourg: Publications Office of the European Union. 30.3.2004:L91. Available from: https://eurlex.europa.eu/LexUriServ/LexUriServ.do?uri=0J:L:2004:091:0 025:0039:EN:PDF

51. EpochCoverter. Week Numbers for 2018. ISO week date standard (ISO-8601); 2018. Available from: https://www. epochconverter.com/weeks/2018

52. Papa A, Papadopoulou E, Chatzixanthouliou C, Glouftsios P, Pappa S, Pervanidou D, et al. Emergence of West Nile virus lineage 2 belonging to the Eastern European subclade, Greece. Arch Virol. 2019;164(6):1673-5. https://doi.org/10.1007/ s00705-019-04243-8 PMID: 30953205

53. Haussig JM, Young JJ, Gossner CM, Mezei E, Bella A, Sirbu A, et al. Early start of the West Nile fever transmission season 2018 in Europe. Euro Surveill. 2018;23(32):1800428. https:// doi.org/10.2807/1560-7917.ES.2018.23.32.1800428 PMID 30107869

54. World Health Organization Regional Office for Europe (WHO/ Europe). West Nile virus infections spike in southern and central Europe. Copenhagen: WHO/Europe; 21 Aug 2018. Available from: http://www.euro.who.int/en/countries/italy/ news/news/2018/8/west-nile-virus-infections-spike-insouthern-and-central-europe

55. European Centre for Medium-Range Weather Forecasts (ECMWF). Copernicus Climate Change Service. European State of the Climate 2018. ECMWF. 2018. Available from: https:// climate.copernicus.eu/european-temperature

56. Mamara A, Chatziapostolou E, Karatarakis N. Significant weather \& climate events in Greece during 2018. Athens: Hellenic National Meteorological Service, Climatology Application Division, Department of Climatology. [Accessed 
15 Jan 2020]. Available from: http://www.emy.gr/emy/en/ pdf/2018_GRsignificantEVENT_en.pdf

57. European Centre for Disease Prevention and Control (ECDC). West Nile virus infection outbreak in humans in Central Macedonia, Greece. July-August 2010. Stockholm: ECDC; Oct 2010. Available from: https://www.ecdc.europa.eu/sites/ default/files/media/en/publications/Publications/1001 MIR_West_Nile_virus_infection_outbreak_humans_Ceñtral_ Macedonia_Greece.pdf

58. Kwan JL, Kluh S, Reisen WK. Antecedent avian immunity limits tangential transmission of West Nile virus to humans. PLoS One. 2012;7(3):e34127. https://doi.org/10.1371/journal. pone.0034127 PMID: 22457819

59. Nemeth NM, Oesterle PT, Bowen RA. Humoral immunity to West Nile virus is long-lasting and protective in the house sparrow (Passer domesticus). Am J Trop Med Hyg. 2009;80(5):864-9. https://doi.org/10.4269/ajtmh.2009.80.864 PMID: 19407139

6o. Chaintoutis SC, Papa A, Pervanidou D, Dovas CI. Evolutionary dynamics of lineage 2 West Nile virus in Europe, 2004-2018: Phylogeny, selection pressure and phylogeography. Mol Phylogenet Evol. 2019;141:106617. https://doi.org/10.1016/j. ympev.2019.106617 PMID: 31521822

61. Young JJ, Coulombier D, Domanović D, Zeller H, Gossner CM, European Union West Nile Fever Working Group. One Health approach for West Nile virus surveillance in the European Union: relevance of equine data for blood safety. Euro Surveill. 2019;24(16):1800349. https://doi.org/10.2807/1560-7917. ES.2019.24.16.1800349 PMID: 31014416

62. Riccardo F, Bolici F, Fafangel M, Jovanovic V, Socan M, Klepac P, et al. Strengthening preparedness for West Nile Virus in Europe following the 2018 transmission season: an ECDC protocol to conduct After Action Reviews. ESCAIDE; 27-29 Nov 2019; Stockholm: ESCAIDE. Available from: https://www.escaide.eu/ sites/default/files/documents/ESCAIDE-abstract-book-2019. pdf

63. Hellenic Statistical Authority. (EL. STAT.). Estimated population by sex and 5 year age groups on 1st January (Years 1991 2012). Piraeus: EL. STAT. [Accessed 15 Jun 2019]. Available from: https://www.statistics.gr/en/statistics/-/publication/ $\mathrm{SPO} 18 /-$

\section{License, supplementary material and copyright}

This is an open-access article distributed under the terms of the Creative Commons Attribution (CC BY 4.0) Licence. You may share and adapt the material, but must give appropriate credit to the source, provide a link to the licence and indicate if changes were made.

Any supplementary material referenced in the article can be found in the online version.

This article is copyright of the authors or their affiliated institutions, 2020. 